\title{
Parental Influence on Pupils' Conflict Responses: \\ A Case Study of Tangenhamo Secondary School in Mt. Darwin District, Zimbabwe
}

\author{
Andrew Katiza \\ akatiza@yahoo.com \\ David Makwerere \\ Department of Peace and Governance \\ Bindura University of Science Education \\ david.makwerere@gmail.com
}

Donwell Dube

Lupane State University

dondube@tsamail.co.za

\section{ABSTRACT}

The study investigated the influence of parents on pupils' conflict responses at Tangenhamo secondary school basing on the Social interdependence theory and Lederach's Moral Imagination theory using the case study method. Parents directly intervene in pupils' conflict and can indirectly influence gender considerations, religion and the extended family interrelationship matrix. The peer influence of adolescence is extensively divorced from parents' factor. Although parents shape gender and religion considerations, individual pupils use them to shape future conflict responses independent to parents. Diversity in factors influencing conflict responses is becoming more pronounced due to media influence and the guidance and counselling offered in schools and the researchers recommend a more diverse conflict resolution partnership including parents in shaping conflict responses of pupils at school. The researchers believe that collaboration between parents and teachers can bring about peace oriented conflict responses in school.

\section{Keywords:}

conflict, conflict response, parents, interdependence, moral imagination

\section{Introduction}

Matma Gandhi once stated, "If we are to reach real peace in this world we shall W have to begin with the children" (Johnson and Johnson, 2009). If we are to develop lasting peace, children need to be educated into competencies, perspectives, 
attitudes, values, and behavioural patterns that will enable them to build and maintain peace.

Parents are important socialization agents that impart social values and social norms. Social norms and values that are desirable influence healthy relationship based on the recognition that within the web of relationships everyone is linked to everyone else (Shonhiwa, 2012). Pupils social norms and values are determined by examples set by significant others and the attitudes they convey to them.

The ways in which parents interact with their children greatly affect later social competencies as guided through reflection-enhancing communication, a considerably effective form of parent-child communication. In reflection-enhancing communication, parental messages encourage children to think about the causes and effects of their actions. These enhancing messages maybe verbal or an action that enable the child to engage in processing how an action emerges from, and also serves to create, the affective and psychological environment that follows the action. Parents engage in explicit encouragement of reflection when they encourage their children to think about causes and consequences of their behaviour as explicitly stated by the parents. After children examine the causes and consequences of their behaviour, they will be able to modify that behaviour in future. The following is an example that demonstrates parental use of reflection-enhancing communication with a child who is struggling with how to respond to a problem with a friend:

When people hurt us we want to call them names. It doesn't do any good though. Next time why don't you tell them you're angry at what they did. Then maybe they won't do it again. If they do, then just don't play with them. Just calling someone a name doesn't make you feel better or your friend. (Applegate et al., 1992, p. 16)

Reflection-enhancing communication refers to the degree to which the parent provides reasons that involve psychological consequences to inspire children to change or understand their behaviour. In the families, the ability of children to modify their own behaviour and to understand the behaviours of others has clear implications for social competence. The literature is replete with information about the critical role of social competence in shaping children's school success (e.g., Johnson and Johnson, Okotoni and Okotoni, ) thus making it important for parents to engage in positive communication styles with children that can promote social competence.

Whereas reflection-enhancing communication is inductive and therefore appeals to the pupils internalized beliefs, the alternative type of communication style would be power assertive. The power-assertive style relies on coercion to direct the pupil to change the behaviour in question the pupil is likely to respond negatively to conflict. Studies have suggested that power-assertive communication is associated with more aggression in pupils, whereas inductive communication is associated with selfsacrifice and humane way leading to internalization of moral principles. This creates room for positive interaction based on the moral imagination gained from parental guidance. Reflection-enhancing communication has been described as complex behaviour that promotes the development of more advanced behaviours and thought processes, such as perspective-taking skills, reasoning, and logic (Applegate et al., 1992), as well as positive peer relationships and psychological well-being (Wilson, 
Whipple, \& Grau, 1996). A home environment characterized by a reflectionenhancing communication style is an important protective factor for pupils in building the blocks for positive conflict resolution in school.

Very few researchers have considered the roles of parents in influencing conflict responses of pupils at school through reflection enhancing communication. For example Johnson and Johnson researched on the influence of interdependence model to find out the conflict management practices in United Kingdom schools. While Desforges and Abouchaar (2003: 20) acknowledge that "parental involvement is a major force in shaping pupils outcomes", they researched on influence of parents on pupils' academic achievement. Neither Johnson P who described parents' parental involvement in school as a "school" input nor Kester $\mathrm{K}$ who researched on peace education in Japanese high schools could focus on influence of parents in conflict behaviour of their children at school. Nor do they include any reference to pupils' conflict responses at school. Carr and Hussey researched on collaborative effects of parents and teachers on student behaviour yet the main focus is on bullying.

In circumstances in which literature that link peace education and conflict resolution mechanisms with pupils in the school, the approach towards peace in the school is limited focusing on the school as the socializing agent. Most of the literature focuses little on the role of social attribute obtained formally and informally from the parents. The focus nowadays is mainly centred on the school, leaving a disaggregated intervention in pupils' conflict management.

\section{Conflicts at school and their impact}

Schools should be relatively safe places, but violent incidents and fear of violence are rampant in schools, yet they have a profound effect on the education process. Schools with high incidences of unresolved conflicts and violence are less effective in educating learners (de Wet, 2007). These schools have lower levels of achievement, higher dropouts' rate, and higher rates of absenteeism (de Wet, 2007). Victimized behaviour has been found to inhibit learner's educational, emotional and psychological orientation, yet pupils who interdepend on each other positively has shown a positive growth in educational, emotional and psychological development (Manguvo et al, 2011). Conflicts in the school breeds both change and further conflicts. Conflicts managed destructively or left unresolved, escalate and consequently interfere in the learning process and playground disharmony (Longaretti and Wilson, 2000). Analysis by Marshall in de Wet (2007), has shown that a response to conflict determine whether the conflict is resolved peacefully or it will explode into violence. According to her, learners who are picked on, made fun on, harassed and humiliated by fellow learners "... build up anger and hatred and explode into violence. On the other hand, a learner facing a similar situation who reports to a peer or teacher is exposed to alternative conflict resolution approaches, leading to a peaceful resolution of the conflict.

Built- in conflicts in learners does not only have immediate negative effects, but often persist into adulthood and support an intergenerational culture of coercion and 
violence (McGregor, 2001). Long term cultured conflict responses in schools; through the "culture of silence" is a training ground for long term conflicts.

\section{The problem}

Death and uncomfortable injuries continue to be recorded in schools. Media in Zimbabwe is replete with violent incidences of children who violently respond to conflicts at school. Incidences of murder, assault, sexual violence and stressful coping mechanisms like dropping out of school continue to be recorded in schools. The violent responses and stressful coping mechanisms not only have immediate effects, but often persist into adulthood and support an intergenerational culture of coercion and violence. Parents are increasingly being excluded or exclude themselves from conflict resolution involving their children leaving it all to the teachers yet Jabri (2006) describes of the need to explore "conflict and change in relation to the specificities of context and not in generic terms" hence the need to investigate the role of parents in influencing both positive and negative reflection enhancing communication in responding to conflict and resultant coping mechanism with a view of paving way for integrative and collaborative pupils conflict responses that too include parents. Parents' collaboration with teachers in influencing pupil conflict responses seem to be the most probable way to reduce the negative effects of conflict in schools.

The development of attitudes and skills begin in the home (Newman, 2005), yet the peace education and conflict resolution approaches at school has little roots in parents involvement. The paper's main objective was to find out the influence of parents on the conflict response style chosen by pupils in a school setting. This is achieved by exploring and assessing pupils' conflict responses at school and the socialization such pupils have received from parents. This is important especially in present scenarios where duties of shaping pupils is almost being completely entrusted to teachers leaving out parents and the family, the first line of socialization.

\section{Methodology and Research Design \\ The Participants}

Six out fifteen diploma holder teachers of considerable teaching experience and dealing with children were interviewed based on both formal and informal interviews. Individual interviews were held with 20 pupil participants systematically selected from pupils observed from the field participating or taking part in a conflict. Standardized open ended interviews were guided by three universal questions that were universal were: describe a conflict you have experienced in this school, how did (the pupil) you resolved or intent to resolve the conflict and describe the role of parents in influencing the type of response described?

The case study approach allows for "how" and "why" questions to be sufficiently addressed. The case study strategy is an "empirical inquiry that investigates a contemporary phenomenon within its real-life context, (where) boundaries between phenomenon and context are not clearly evident, and (one in 
which) multiple sources of evidence are used". A case study focuses on a bounded system, under natural conditions, so that the system is understood in its habitat. Zainal (2007) contend that, the case study is applicable method in a small area or in situations with a very limited number of individuals as the subject of study. The true essence of using a case study according to Zainal (2007), drawing from a view from Yin, is "to explore and investigate contemporary real life phenomenon through a detailed contextual analysis of limited number of events or conditions, and their relationships". Yin in Tellis (1997) and Zainal (2007) defines case study research method "as an empirical inquiry that investigates a contemporary phenomenon within a real life context; when the boundaries between phenomenon and context are not clearly evident; and in which multiple sources of evidence are used."

The case study based on pupil and teacher interviews carried out together with participant observation and document analysis. The use of multi-methods generated a comprehensive understanding of the complexity of pupils' social interactions and pupils conflict responses.

The credibility of the research was increased through an extended period with informants. The informants were accustomed to the researchers. A high rapport existed between informants and the researchers. In addition to rapport, in some instances the researcher used hypothetical cases and the reframing of questions in order to elicit more personal responses. Triangulation of methods involved using the interview and observation methods.

\section{Literature Review}

In discussing the influence of parents on the conflict responses as based on reflection enhancing communication, the moral imagination model was employed. The model links a person's social geography to conflict and the responses employed as influenced by such social geography. The term "moral" is concerned with goodness or badness of human character or behaviour or a concept that makes a distinction between what is wrong and right. "Imagination" is a mental faculty forming images or concepts of external objects with the ability to paint persuasive mental pictures of good and bad human character and behaviour and to be creative in so doing (Kyoon, 2009).

Moral imagination in conflict situations is described by Lederach, as the capacity to recognize turning points and possibilities in order to venture down unknown paths and create what does not yet exist (Lederach, 2005). Conflict responses must be rooted in day-to-day challenges of conflict designed to transcend destructive conflicts as motivated by parents enhancing communication. Moral imagination gives capacity to capture reflection enhancing communication that lead to generation of constructive conflict responses.

Parents who possess the capacity of moral imagination transfer reflection enhancing communication that leads to pupils imagining themselves in a web of relationships, that includes even perceived enemies in "mutuality and interconnectedness" (Lederach, 1995). The reflection enhancing communication in moral imagination cultivated by parents shapes the ability of individuals in conflict to 
rise above the "we" and "them" divisions and reach beyond accepted expected responses, meanings and values (Maise, 2010). Accordingly, parents that fail to confer reflection enhancing communication fail to impart paradoxical curiosity in their children- paradoxical curiosity that confer the ability to respect social complexities of events, then seek relationships that are beyond those in existence and helping to discover aspects that holds apparently opposed social forces together. Human being is a product of the way people interpret their worlds (Yates, 2004: 157; Maise, 2010).

The theory of moral imagination is a relational centred theory, that views human community as a matter of crisscrossing connections between people, their lives, activities and patterns that shape new ways of life. Pupils' social geography through parents' reflection-enhancing communication shapes their moral geography that capacitate them to deal with events including conflicts. The conflicts occur within the web of relationships hence the reflection enhancing communication opens up social space or social geography in which responses are shaped from every strand and linkage of the web. Peace oriented responses should be based on available attachment points that make the relationship stick. Oppositely, parents reflection enhancing communication may fail to capture the available attachment points that make relationships stick. Does the parents' social geography and reflection enhancing communication have effect on pupils' responses at school?

\section{Social Interdependence Theory}

Cooperation and competition are the two dimensions that underlie the social interdependence theory. Social interdependence is a condition accomplished only when each individual goals is affected by the action of the other (Coleman and Deutsch, 2001; Johnson and Johnson, 2009). There are two types of interdependence: positive interdependence based on cooperative relationship and a negative interdependence based on competition.

Central to the creation of cooperative relationship are psychological processes of firstly, substitutability- the degree to which actions of one person are substituted for actions of another person. Secondly, the aspect of inducibility- an openness to being influenced and to influence others and thirdly, psychological aspect of positive catharsis, which describes an investment of positive psychological energy in objects outside of oneself (Coleman and Deutsch, 2001; Johnson and Johnson, 2009).

Parents induce behaviour and choice of behaviour on their children through reflection enhancing communication. Children, in future has the potential to substitute behaviour from the one imparted by parents through reflection enhancing communication or can give a cathartic responses that exists outside social and moral geography. 


\section{Conceptual Clarification}

\section{Conflict}

Lederach (1995:17), defines social conflict as a, “...phenomenon of human creation, lodged naturally in relationships. It is a phenomenon that transforms events, the relationship in which conflict occurs, and indeed its very creators. It is necessary element in transformative human construction and reconstruction of social organization and realities." It can affect self-esteem, emotional stability, and capacity to perceive accurately, components that affect negatively responses to conflict.

Therefore, social conflicts emerge and develop on the basis of meanings and interpretation which attach people action and events and secondly, social conflicts are rooted in people's culture- peoples' accumulated and shared knowledge that is used to respond to social realities.

Within the school context, conflict is defined as a verbal or physical struggle between two or more children trying to achieve their own goals. It is this definition which will be used throughout this project (Longaretti and Wilson, 2000).

\section{Conflict response}

A behaviour exhibited by an individual towards another individual in response to a conflict. The behaviour can be physical or verbal.

\section{Peace}

Peace can be defined as an existence of harmonious relationship. Peace confers stability, happiness and tranquillity to an individual.

Peace-making is the action taken to bring hostile parties to an agreement through peaceful means.

\section{Pupils' Perceptions of Conflict}

Attitudes and skills can be nurtured in pupils at school and home. Nurturing selfesteem, developing social relationships and building self- autonomy and selfdiscipline are the foundation of peace education. Self-esteem is necessary for anyone to care for others; no pupil can be compassionate towards others unless he/she is secure about his/her own self-worth. Self-esteem enables for positive relationships in social interdependence relations, allowing for tolerance of others opinions and differences. Self-esteem begins with the development of trust in oneself, and in significant others, exposing one's inadequacies and their ultimate acceptance, learning to deal with emotions of fear, anger and jealousy positively communicating in verbal and non-verbal language, listening patiently and actively, acquiring autonomy and responsibilities. Self-esteem is modelled and affirmed through provision of choices, guidance towards self-discipline, encouragement and support.

Avoidance of the situation that causes the conflict is an example of an interpersonal approach (Dodo et al, 2010). Another way of coping with conflict is through smoothing, emphasizing the areas of agreement and common goals and deemphasizing disagreements. A third way according to Kyoon, 2009 is forcing, 
pushing one's own view on others; this, of course, will cause overt or covert resistance. A traditional way of coping with conflict is to compromise, agreeing in part with the other person's view or demand. The biggest problem in developing the institutions of conflict control in organization is to develop an action of plan to identify conflicts at its initial stage.

Conflict situations are frequently allowed to develop to almost unmanageable proportions before anything is done about them, by this time it is often too late to resolve the conflict by peaceable and procedural means.

Longaretti and Wilson (2000), argued that the best way to handle conflicts objectively is to follow six process Thomas- Kilmann model that involves describing the conflict situation to the other person, asking the other person how he sees the conflict situation, responding the way the other person sees the situation, jointly deciding how to resolve the conflict, making commitment to resolve the conflicts, and promising to be committed in future to continue resolving conflicts, which might arise. Another way of coping with organizational conflicts is to make structural changes. This means modifying and integrating the objectives of groups with different viewpoints.

\section{Relational problem solving}

In resolving conflicts, actors may use collaboration, bargaining and the power play methodology in reaching consensus. Collaboration involves people surfacing their differences (get them out in the open) and then work on the problems until they have attained mutually satisfactory solutions. This approach assumes that people will be motivated to expend the time and energy for such problem-solving activity. Bargaining on the other hand assumes that neither party will emerge satisfied from the confrontation but that both, through negotiation, can get something they do not have at the start, or more of something they need, usually by giving up something of lesser importance. One party generally wins more than they need, usually by giving up something of lesser importance. One party generally wins more than the other; by the skilful use of tactical trades, he can get the maximum possible from the other side. Third approach is Power Play, which differs from the other two approaches because its emphasis is on self-interest. Whereas, in collaboration and bargaining the two sides come together to try to resolve their problems, when power is the dominant mode, the actions are unilateral or in coalitions acting unilaterally.

\section{Conflict responses as used by pupils in schools}

Research indicates that different people use different strategies and responses to manage conflict (Longaretti and Wilson, 2000). Kilmann and Thomas in Longaretti and Wilson (2000), suggest that conflict is goal oriented; hence the importance of personal goals affects a person's decision to use a particular response.

Factors which influence the development of pupil perception and responses to a conflict include past experiences, socialization and exposure to and modelling of different conflict responses. Pupils' conflict responses may be influenced by how he/she sees disputes handled around him/her. 
Pupils do not come to school with social skills; they need to collaborate effectively. Pupils physiologically respond to conflict by "taking anyone who comes their way" or by "getting away from the conflict." Thus the importance of peace education in the school with the teacher as the role model.

\section{Research findings}

\section{Type of conflict occurring at school}

The type of conflicts vary in there occurrence. Gender based conflicts occur with boys expressing power as a coercive measure to induce compliance on girls. Value conflicts were also identified in cases involving the religious sect members who refused to work in tobacco operations. But most of the conflicts that occur between pupils and other pupils are uncomplicated conflict of possession and belonging to a group.

The result show that pupil to pupil conflicts are usually spontaneous resulting from emotions especially anger that build up during the conflict. The responses to such conflict are also spontaneous making contention and competition the most used responses.

Teacher to pupil conflicts are more structured resulting from disobeying orders and not doing school work. The conflicts are premised on asymmetries in power relations.

\section{Pupils conflict responses at school}

Pupils mostly use contention and avoidance as the main conflict responses. The contention responses mostly include hitting and swearing, not shaking hands, not greeting, not responding while maintaining a condescending eye contact and shouting vulgar. Most of the respondents use externalizing responses that are linked to delinquent activities, aggression, and hyperactivity. Violent responses include episodes of punching and kicking that result in somatic injury.

Violent responses were found not to always lead to physical injuries; it was often associated with intimidation, threats and perceptions of fear and vulnerability. Distinguishable categories of violent responses which emerged are; physical compulsion and physical injury where in conflict between two or more individuals in which at least one of the parties use bodily force or weapons to cause intentional harm, or at least threaten such harm to the other side for example the case of Temptation and Bernard. The spectrum of the harm ranges from a slap in the face, a box in the head and bruises. The other categories involves verbal aggression especially degradation of an individual by use of insults.

\section{Influence of parents on pupils conflict responses}

The influence is diverse. Parents influence gender considerations, values with the main one being the religious values and the societal considerations of interwoven relations. Parents also intervene directly in physical fights with the other conflicting party. Violent behaviour such as punching and kicking are often learned from 
observing others (Newman, 2005). The influence of parents on pupils' conflict responses is consistent with Gerald Patterson's social interaction model that explains a context in which a mother's coercive behaviour leads to child's counter application of the same coercive behaviour on other children. "Abusive home environments can inhibit growth of social cognitive growth skills needed to understand the intentions of others" (ibid).

\section{Pupils' perception of conflict}

Conflict was implicitly viewed as an actively aggressive event that involved "clapped him twice", "kicked me as he wishes", "hit me with a slasher" and "grabbed her by the collar". Conflict reported by pupil respondents was also an explicitly an event that leads to discord, situations of "we are no longer in talking terms" and result in distressing outcomes that include "anger", sadness and sometimes frustration.

Conflict is viewed as bad. It spoils relations and lead to emotional and somatic injury. Incidences of "crying", living under "intense emotional stress", "hatred" and living with bruises and wounds for is common among pupils. This is in line with findings by Okotoni and Okotoni (2003: 34) who found out that students and teachers in Nigerian schools they studied view conflict as "unwanted disagreements". Parents promote "usahwira" relationship that is mediatory. After a physical scuffle a boy and a girl "sahwiras" buried the hatchet. Indeed, conflict can be a sign of basic pathology, but stability in itself may be a symptom of social stagnation with potential to produce decadence (Obiekwe, 2009).

\section{Conflict responses used by pupils at school}

Conflict responses exhibited by pupils are modelled along past experiences, socialization and exposure to and modelling of different conflict responses. Conflict responses are influenced by reflection enhancing communication. Pupils use a variety of simple, rather than complex and advanced conflict responses and that they responded to conflict rigidly and reflexively.

\section{Contention}

The use of force, both physical and verbal threats and fighting is common. Scenarios of "punched me twice", "slapped him twice" and "yelled at me...scolding me to attract attention of teachers" shows the intent to protect self-interests. Parents slap, scold and yell at their children in times of disagreements. In events where balance of power in power relations favours one side, the stronger party use influence to assert authority (Coleman and Deutsch, 2001). Contention is an example of imposed peace described by Johnson and Johnson (2006: 224) as a form of negative interdependence based on domination, power, imposition, and enforcement. Parents directly encourage hostilities by joining fights, encouraging violent responses by girls towards more dominant part, males and indirectly influence contention by yelling, kicking and scolding their children when in conflict. 


\section{Smoothing}

Parents influence "truth speaking and asking for forgiveness" as a way of ending a conflict and move on. Mothers are reported to encourage lowering the "high pitched voice" which implies conflict smoothing in order for one to get on well with others. Furthermore, parents influence peace-making in children by nurturing self-esteem and self-discipline. These peace-making concepts are nurtured at a very young age, beginning in infancy (Quisumbing, 2000). Peace-making concepts like "truth speaking and asking for forgiveness" are examples of reflection enhancing communication that promote mutual interdependence.

\section{Avoiding}

Avoidance leaves conflicts unresolved in the long term. Parents influence avoidance by directly telling their children to keep quiet and to ignore the conflict. Parents give comments like "what will you gain" or "what will you lose". In homes parents do not confront each other in front of children. Avoiding conflicts this way is a form of reflection enhancing communication. Pupils become socialized and use the skills in future as a team or as individuals. As a group soccer players remove soccer uniforms and move out of the pitch in protest and as individuals pupils "run away", "report the case to the teacher" or are "absent for two days" to avoid conflict. Research done by Smith, Inder and Ratcliffe in United States of America found out that in about one third of the conflicts, pupils withdrew from the conflict (Longaretti and Wilson, 2000). Studies carried out by Johnson and Johnson (1996) on primary aged pupils found out that the most frequently used responses used by the pupils in conflict were telling the teacher and withdrawing from the conflict.

Peace is a relationship variable, not a trait and require positive interdependence of individuals in establishing and maintaining it. Parents encourage interdependence basing on the extended family concept. A pupil who avoids conflicts end up with intense emotional stress and possibly fights. The pupils "settle score" with each other. Johnson and Johnson (2006: 224) and Obiekwe (2009) provide a refreshing description on peace as "an encounter" between conflicting parties. As a relationship, peace cannot be maintained by separation, isolation or building barriers between conflicting parties. Avoidance of a conflict may temporarily reduce tensions but will not establish positive interdependent relationship implied by Deutch theory of social interdependence.

\section{Anger in conflict}

Emotions are a factor shaping conflict responses that has to be considered. Parents directly or indirectly influence emotions and anger through reflection enhancing communication. Anger is present in every conflict (Doer 2004: 71). It may be hidden or obvious but it is present. Depending on the depth of the conflict, other emotions may also be present with pupils being frustrated on several instances. As the emotional level increases between social actors, the conflict responses tend to competitively and violently inclined resulting in physical and further emotional injury. The physical injury is usually not an exception since rational thought 
processes are usually at minimum during altercations involving higher emotional levels.

\section{Influence of moral geography and perceptions to the conflict as a factor shaping conflict responses.}

Perceptions play an important role, as emotions spiral upwards or downwards. Doer (2004:72) is of the opinion that the important influence on emotions is the perception of intentionality. This may determine if the social actor chooses anger or empathy towards the other conflicting party. Conversely, the choice of emotions may be the deciding factor in whether or not the conflict escalates or de-escalates.

Parents shape the perception of intentionality which is expressed through conflict responses. Children are not born with preconceived ideas of alienation or marginalization, with feelings of superiority or inferiority, with discrimination, bias or prejudice, with hatred, revenge or violence (Quisumbing, 2000). They learn these through interaction with adults, media and their culture.

Parents shape the moral geography of their children so as to coexist with the greater community. Parents cultivate the living together concept "you are because we are" a concept that is relational. It is within this locus that the pupil approach conflict with teachers and other pupils hence the prevalence of smoothing as his most used conflict response.

Self-autonomy and self-esteem are taught and encouraged by parents, attributes that are help in conflict smoothening since the individual is able to deal with others, is tolerant to diverse opinions and differences (Quisumbing, 2000).

Comments presented by teachers about pupils who "... want to bring war veteran mentality into the school". Of boy pupils who want to bring "their fathers behaviour" into the school and of pupils who exhibit their parents behaviour shows that parents influence behaviour of their children when in conflict. The influence of parents on pupils' conflict responses is consistent with Gerald Patterson's social interaction model that explains a context in which a mother's coercive behaviour leads to child's counter application of the same coercive behaviour on other children. "Abusive home environments can inhibit growth of social cognitive growth skills needed to understand the intentions of others" (ibid). According to Harris (undated) violent behaviours such as punching and kicking are learned by observing significant others who are usually one's parents.

Furthermore in resolving rumours mothers asks children to "keep quiet about it" and parents confront the other conflicting party. Most children socialized in such a matter usually let go and later confront the issue usually leading to scuffles.

In a pregnancy rumour, when asked about the state of their interpersonal relationship a pupil commented that: "I can't talk to a (derogatory). If my mother cannot talk to her and her mother then why should I?" Parents use the laissez faire approach when bringing up their children. Such pupils who are "given their positions" tend to respond violently to conflict.

According to Kyoon (2009) the significant individuals invoke negative memories of relationships perpetuating or breeding further conflict. The relational 
space will be closed making positive interaction difficult. In the heat of a conflict parties may entrench positions and place themselves in positions where they fail to transcend the conflict or to invoke the moral imagination leading to scuffles.

\section{Parents influence on gender considerations}

Parents shape immediate perceptions of their children who are in conflict through perception enhancing communication. One of the perception issues shaped by parents is that of gender. Gender is defined by Newman (2005: 150) as a term that "designates masculinity and femininity". Gender stereotypes developed by children are used to guide their perceptions and activities. Parents designate violent conflict responses based on gender commendable especially when done by girls towards boys. A girl who clubbed a boy with a broom stick was recommended to have "done right to avoid more beating" since the other conflicting party was a boy. A pupil commented saying "I used force against him" because "he is male". This concur with the observations by Newman (2005: 152) parents tend to encourage more gendertyped activities (and responses to conflict) as their children grow older.

\section{Parents influence on cooperative approach}

Pupils conflict responses are influenced by the nurturing they get through their childhood. According to the description of Newman (2005: 134), "We are who we are because of the way we were treated while growing up". Human beings reflect society influences. Parents according to McGregor (2001) nurture self-esteem, self-autonomy and self-discipline. Parents encourage peaceful resolution of conflict not "to end conflict through use of hands". Further, parents encourage negotiation for the pupils to "discuss and resolve the matter" with the other conflicting party. Success of resolving conflict by negotiation is achievable given that pupils are neighbours who must cultivate peaceful relationship and peaceful images. Research by Longaretti and Wilson (2000) found out that teachers believed that encouraging pupils to collaboratively talk to each other over a conflict stopped unpleasantness and negative behaviour.

Lederach in Kyoon (2009) describes social space as shaping conflict responses through the nodal points of the relationship strands. The laissez faire approach by the parents has been described by the teacher as "giving the children their positions". The status conferred result in pupils' responses being contending in nature. Contemporary research conducted in schools in the United States America and New Zealand highlighted contending as the most preferred strategy used by pupils' who come from families lacking cohesion (Longaretti and Wilson, 2000).

\section{Influence of parents and religion on conflict responses}

Religion produces one of the most contentious identity based conflicts and followers tend to be aggressive and unyielding- assertive (Coleman and Deutch, 2001). Pupils withdrew from an assigned duty and approached the emotionally asking him to reverse the decision to make them work in tobacco operations. Parents' protestations have been registered in the school asking for their children exclusion from tobacco 
operations. This response was described by Okotoni and Okotoni (2003: 31) and Coleman and Deutsch (2001) compulsively revealing response that is common in identity based conflicts.

Religion confers people with values which differentiate between right and wrong or good and evil (Doer, 2004: 79). These values include religion and develop through the process of enculturation. The values derived from parents govern the actions and reactions of children at school. the values also dictate appropriate and inappropriate behaviour in school for example most of the Johane Marange boys jumped through the windows "to avoid" being injected with a vaccine during a nationwide vaccination campaign in schools. Pupils are given instructions by parents to "run away" from being vaccinated or risk being beaten and shamed at home. Parents do this to safeguard their positions and status in the church. Religion influences creation of an "in- group" and "out- group", resulting in parents influencing their children to foster this division even at school.

\section{Influence of presence of other pupils}

The presence of others has shown to sometimes enhance a positive conflict response and sometimes enhances a negative response. A pupil "grabbed another's collar" and told her to "stand up" with confidence because her "team stood by" waiting to intervene in the fight. Contention and avoidance are the two most likely resultant responses resulting from presence of others. Pupils shout vulgar words in order to attract attention of other pupils and teachers around. Comments by other pupils encourage violent reactions for example a comment by several pupils of a "hurtful clap" resulted in a violent reaction that ended up in a scuffle and injuries. Performing positively in presence of others is termed the social facilitation effect and performing negatively in presence of others is termed social inhibition effect (Hlatswayo et al, 2010:69).

\section{The storm and stress}

Most of the informants were adolescents who are in the period of storm and stress. A teacher commented "if you ask them why they did it (shouting obscenities at the teacher) they cannot convincingly explain" otherwise they state "it just happened". The adolescent period is characterized by excessive anger and outbursts. Pupils "having a lot in my head" and "swirling head" have unresolved problems both at home and in the school.

\section{Conclusion}

Parents influence gender considerations, religious considerations and moral consideration of conflicting parties' relationships. Parents influence reflection enhancing communication through imparting and reinforcing social skills and the development of identity. Identity consists of our membership to various social groups that include gender and religion. These characteristics are social constructions- a product of our social geography and the significant others in in our lives (Newman, 2005: 134). 
Parents have the capability of influencing a compromise response from conflicting pupils. By invoking imagination that links the pupils' relationships, parents influence "thinking over a conflict" by pupils leading to conflict smoothing (Doer. 2004; Johnson, 2003: 35).

Most of the pupil- pupil and pupil- teacher conflict are responded to by pupils using contention. Most of the pupils' conflict responses involve the use of power and aggressive behaviour in attaining their self ends in a conflict. Johnson describes the behaviour in contention as involving "hostility and sarcasm, force one's feelings, beliefs and ideas on others" and "shifting responsibilities by blaming others". Intense and tenacious enmity emerges as a result of contention conflict response. Although parents influence avoidance, it only postpones conflict which needs to be solved in future. Avoided conflicts will continue with potentially disastrous consequences in future which lead to broken down relationships, physical injuries, breaking down of furniture, brooms and torn books.

\section{Recommendations}

The influence of parents in conflict responses need to be recognized and incorporated in influencing positive interdependence of pupils' relationships. Parents are an important school input whose collaborative influence in the school settings in influencing pupils' conflict responses should be utilized to achieve peace. Collaboration should include engendering of parental empowerment. Moreover, peace education with a human rights dimension should be integrated into the school curriculum to teach pupils peace issues and conflict resolution approaches.

The research was carried out on one rural school. It would be advantageous to expand this kind of research to include several other schools. It would be helpful to compare dynamics of parental influence on pupils' conflict responses within a rural school and urban school. Further, the influence of the media on attitude, myth, values and stereotypes need to be explored given the proliferation of mobile phones and internet.

\section{References}

Aitken, S. C and Herman T.C. Literature Review on Qualitative Methods and Standards for Engaging and Studying Independent children in Developing World. Innocenti Working Paper. IWP2009- 05. 2009. www.unicef-irc.org/publications/pdf/iwp_2009_05.pdf 24/04/2012

A Culture of Peace. Educational Innovation and Information. UNESCO. 1999. No. 100. Case study as a Research Methodology. http://www.languageswithoutlimits.co.uk/resources/AntChap3.pdf downloaded 21/02/12

Casley, D. J and Kumar, K. (1989). The Collection, Analysis and Monitoring and Evaluation data. World Bank Publication

Chadwick, B. A; Bahr, H. M and Albreicht, S. L (1984). Social Science Research Methods. Prentice Hall. London. 
Coleman, P and Deutsch, M. (2001). Introducing co-operation and conflict resolution in schools: A systems approach. In Christie, D.J, Wagner, R.V and Winter, D.D.N (Eds.). Peace, conflict and violence: Peace psychology for the $21^{\text {th }}$ century. N.J. Prentice- Hall.

Desforges, C and Abouchaar, A. the impact of parental involvement, parental support and Family Education on Pupils Achievement and Adjustment: A Literature Review. Report Number 433. 2003

De Wet, C (2007). School violence in Lesotho: the perceptions, experiences and observations of a group of learners. South African Journal of Education. Vol. 27. 2007: 673- 689.

Doer. J. C. Dealing with cross- cultural conflict in a multicultural organization: An education perspective. 2004. Master Thesis. University of South Africa.

Dodo, O; Mateura- Chawana, Z and Sadomba, F (2010). Conflict Analysis and Transformation. Module MSPL 501

Five Misunderstanding about Case Research. http://flybjerg.plan.aau.dk/Publications2006/0604FIVEMISPUBL2006.pdf $\quad$ downloaded $22 / 02 / 12$

Funk, N. C. Peace Paradigms: Five Approaches to Peace. Gandhi Marg, October- December 2002, Volume. 24, No.3

Glazer, B. G. (2004) "Naturalist Inquiry" and Grounded Theory. www.qualitativeresearch.net/index.php/fqs/article.../1412 accessed 22/02/2012

Harris, I. Conflict Resolution Education. Teach kids peace from harmony. www.iprafoundation.org/ $05 / 11 / 2011$

Jabri, V. Revisiting Change and Conflict: On Underlying Assumptions and De- Politicisation of Conflict Resolution. Bergof Research Center for Constructive Management - Bergof Handbook Dialogue No. 5

Jeffrey, J (1995). Broad and Narrow Socialization: The Family in the Context of a Cultural Theory. Journal of Marriage and the Family 57(3):617- 28

Johnson, D.W and Johnson, R.T. peace Education in the Classroom: Creating effective Peace Education Programs. University of Minnesota. 2006: 223- 241.

Johnson, P. Conflict and the school leader: Expert or Novice. Journal of Research for Educational Leaders 2003, Volume 1, Number 3 Pages 28- 45.

Kester, K: Developing Peace Education Programs- Beyond Ethnocentrism and Violence. Peace Prints: South Asian Journal of Peacebuilding, Vol. 1, No. 1: 2008

Krefting, L. Rigor in Qualitative Research: The Assessment of Trustworthiness. American Journal of Occupational Therapy, 1991, Volume 45, Number 3. Page 214- 222 http://ajot.aotapress.net/content/45B/214.full.pdf accessed 26/04/2012

Maiese, M (2003). "Levels of Action.” Beyond Intractability. Burgess, G and Burgess, H. Conflict Research Consortium, University of Colorado, Boulder. www.beyondintractability.org/essay/hierarchical_intervention_levels/ 
Manguvo, A; Whitney, S. D. and Chareka, O. The crisis of misbehaviour in Zimbabwean public schools: Teachers' perceptions on impact of macro socioeconomic challenges. International Journal of Education Administration and Policy Studies Vol. 2(4), pp. 40- 44

McGregor, S. (2001). Leadership for the Human Family: Reflective Human Action for a Culture of Peace. Nova Scotia. Canada.

Newman (2005). Socialization: Building Identity. www. Pineforge.com/upmdata/9006_Chapter_5.pdf. 03/11/2011

Obiekwe, K. In Search of Appropriate Peacemaking/Peacebuilding Paradigm in Dealing with Africa's Intrastate Violent Conflicts: Considering Lederach's Faith- based Conflict Transformation and Peacebuilding Approach. Journal of Peace, Conflict and Development, Issue 132009

Okotoni, O and Okotoni, A. Conflict Management in secondary schools in Osuni State, Nigeria. Nordic Journal of African Studies 12(1): 23- 38 (2003)

"Pyramid of Actors and Approaches to Peacebuilding" Self- Learning -Course No 6: Academy for Conflict Transformation

Peace education http://en.wikipedia.org/wiki/Peace_education 26/10/2011

Quisumbing, L. R (2000). Educating Young Children for a Peaceful World. Second World Forum on Early Care and Education, Singapore

School violence. $\quad$ http://en. wikipedia.org/w/index.php?title $=$ School violence\&oldid $=461147568$ downloaded 26/11/11

Soy, S.K (1997). The Case study as a Research Method. University of Texas. Austin. http//www.glis.utexas.edu/ ssoy/usesusers/1391 dlb.htm downloaded 12/02/12

Ssenkumba, M (2010). A baseline survey report on: School Based Peace Education and Guidance and Counselling in Secondary Schools in Northern Uganda. Stability, Peace and Reconciliation in Northern Uganda Project.

Socialization.

http://en.wikibooks.org/w/index.php?title=Introduction_to_Sociology/Socialization\&oldid=217 $\underline{4296}$

Tellis, W. Application of Case Study Methodology. The Qualitative Report, Volume 3, September, 1997. http://www.nova.edu/ssss/QR/QR3-3/tellis2.html downloaded 22/02/12

The Foundation Coalition: Understanding conflict and conflict management. http://www.foundationcoalition/teams downloaded 01/12/11

Troachim, W. M. K. Qualitative Validity.

www.anglefire.com/thefone/shucohortviii/images/TrustworthyPaper accessed 26/04/2012.

Yates, S. J (2004). Doing Social Science Research. $1^{\text {st }}$ edition. Sage Publication. London. Zainal, Z. The case study as a research method. Journal Kemanusiaan bil9. Jun 2007. http://eprints.utm.my/8221/1/ZZainal2007-case studyas aResearch.pdf downloaded 21/02/12 